\section{Mastectomy versus conservative surgical treatment: the impact on the quality of life of women with breast cancer}

\section{Mastectomia versus tratamento cirúrgico conservador: impacto na qualidade de vida de mulheres com câncer mamário}

Daniela Francescato Veiga 1

Fabíola Soares Moreira Campos 2

Leda Marques Ribeiro 3

Ivanildo Archangelo Junior 4

Joel Veiga Filho 5

Yara Juliano 6

Miguel Sabino Neto 7

Lydia Masako Ferreira 8

1-6 Universidade do Vale do Sapucaí. Avenida Pref. Tuany Toledo, 470. Pouso Alegre, MG, Brasil. CEP 37.550-000.

E-mail: danifveiga@uol.com.br

7,8 Universidade Federal de São Paulo. São Paulo, SP, Brasil

\section{Resumo}

Objetivos: comparar o impacto da mastectomia e da cirurgia conservadora na qualidade de vida de pacientes com câncer mamário.

Métodos: avaliou-se qualidade de vida de pacientes submetidas à mastectomia ou à mastectomia segmentar, no Hospital das Clínicas de Pouso Alegre, Minas Gerais, Brasil, utilizando-se o SF-36. As pacientes foram estratificadas quanto à idade $(\leq 50$ anos $e>50$ anos) e escolaridade ( $\leq 8$ anos $e>8$ anos). Aplicou-se o teste de Mann-Whitney para comparar os grupos quanto aos domínios do SF-36, idade e escolaridade.

Resultados: observou-se diferença significante entre os grupos nos domínios "capacidade funcional" $(p=0,04)$ e "dor" $(p=0,01)$ : as pacientes mastectomizadas com piores resultados. Pacientes mastectomizadas mais jovens apresentaram pior qualidade de vida em "capacidade funcional" $(p=0,03)$, "dor" $(p=0,01)$ e "aspectos sociais" ( $p=0,01) ;$ as submetidas à cirurgia conservadora, com mais de 50 anos, resultado pior em "aspectos emocionais" $(p=0,05)$. Pacientes mastectomizadas com menor escolaridade apresentaram escores menores em "capacidade funcional" $(p=0,01)$, "aspectos físicos" $(p=0,05) e$ "dor" $(p=0,05)$. Entre as que frequentaram a escola por mais de oito anos, as mastectomizadas pontuaram menos no domínio "dor" $(p=0,04)$.

Conclusões: pacientes mastectomizadas apresentaram piores resultados no componente físico da qualidade de vida, e este impacto negativo foi mais acentuado entre pacientes mais jovens e com menor escolaridade.

Palavras-chave Neoplasias da mama, Mastectomia, Mastectomia segmentar, Qualidade de vida 


\section{Introduction}

Breast cancer is an important cause of morbidity and mortality among women and, in recent years, incidence of this disease has increased progressively in Brazil. ${ }^{1}$ It is estimated that in 2008 there will be more than 49,000 new cases of breast cancer among women in the country. ${ }^{2}$

Surgical treatment of breast cancer has been described for centuries. Historical analysis of this treatment reveals that the efficiency and extent of surgery has always been a source of controversy. 3

In the early $20^{\text {th }}$ century, Halsted established radical mastectomy as the primary method of treatment for breast cancer and this view persisted for the following seventy years. 4 In 1948, Patey and Dyson introduced a modified form of radical mastectomy, reducing the number of cutaneous resections and preserving the pectoralis major muscle, thereby reducing the cosmetic impact of the procedure without lowering the survival rate of patients. 5

The value accorded the breasts as symbols of femininity, sensuality and maternity means that mastectomy is considered a drastic step in the treatment of breast cancer, from a psychological point of view, adversely affecting the self-esteem and body image of patients. 6-8 This has led to a search for alternative methods and the supremacy of Halsted's principles was gradually undermined, due to advances in radiotherapy, hormone therapy, chemotherapy and the development of anatompathological studies allowing more accurate investigations of surgical margins and more recently of sentinel lymph nodes. 9

From the 1980 s on, conservative treatment of breast cancer came to be widely used around the world. This change was based on large prospective randomized studies, which showed that survival rates are not related to the type of surgery, whether radical or conservative. ${ }^{10-12}$ Many patients prefer conservative surgery, because it is less mutilating. 6,13 Others, meanwhile, prefer radical treatment, for fear of recurrence of the disease. ${ }^{14}$

Nowadays, in an increasingly competitive health care environment, patient satisfaction has become a subject of considerable interest. An increasing number of researchers, health-care providers and patients are therefore using patient satisfaction and quality of life to assess the efficacy of medical interventions. ${ }^{12,15}$

In research involving patients, particularly those with cancer, it is important that psycho-social quality of life indicators be used by the doctors caring for these patients. 16 For this reason, the present study aims to compare the impact of mastectomy and conservative surgery on the quality of life patients with breast cancer.

\section{Methods}

Between December 2005 and December 2006, patients who had undergone, at least one year before, a modified radical mastectomy as described by Patey \& Dyson were selected consecutively from the mastology outpatients clinics of Hospital das Clínicas da Universidade do Vale do Sapucaí (UNIVÁS), Pouso Alegre, in the Brazilian State of Minas Gerais, ${ }^{5}$ and these were allocated to Group I of this study, while those who had undergone conservative breat cancer surgery (quadrantectomy or sectorectomy), 10 were allocated to Group II. Patients undergoing surgery less than one year previously, still undergoing adjuvant treatment (chemotherapy or radiotherapy), with diagnosed recurrence or metastases, who had undergone some procedure to reconstruct the breast or who did not wish to participate in the study were excluded.

The sample was selected on the grounds of convenience, comprising all patients who fulfilled the inclusion criteria and who attended the mastology outpatients clinics for oncological follow-up in the period covered by the study. After signing the free informed consent form, the patients were evaluated as part of a cross-sectional study.

To evaluate the quality of life of patients, the Brazilian version of the Medical Outcomes Study 36-item Short-Form Health Survey (SF-36) was used.17 SF-36 is a generic tool for assessing quality of life, derived initially from a questionnaire tested on more than 22,000 patients, as part of a large-scale multi-center health assessment study (The Medical Outcomes Study - MOS). ${ }^{18}$ This is at present the most widely used generic tool for assessment of quality of life around the world. ${ }^{19}$ SF-36 was translated, culturally adapted and validated for use in Brazil by Ciconelli et al., 16 in 1999.

SF-36 comprises 35 items organized around ten questions dealing with eight quality of life issues (physical functioning, role physical, pain, health perception, vitality, social functioning, role emotional and mental health), and one further question comparing the current state of health with that a year previously. With the exception of the last, all questions refer to quality of life in the four years preceding the application of the questionnaire. 17

To evaluate the results a score is given for each question (individual values for each item, as described by the authors of the original). 18 These 
figures are then transformed into a scale from 0 to 100 , where zero represents the worst possible quality of life for this domain and 100 the best. Each domain is analyzed separately, thereby giving rise to eight scales from 0 to 100 , one for each quality of life domain studied. 17

The questionnaires were applied during an interview, always conducted by the same researchers, who were not involved in the cancer treatment of the patients.

Clinical and socio-demographic data were collected from all patients and for analysis of the results, each group was stratified according to age (up to 50 years and over 50 years of age) and years of schooling (up to eight years and over eight years).

This study project was approved by the Research Ethics Committee of Universidade do Vale do Sapucaí (UNIVÁS).

Given the nature of the variables (scores) nonparametric statistics were used. The Mann-Whitney test was applied to compare the two groups with regard to the SF-36 domains, age and schooling. 20

The confidence level for rejection of the null hypothesis was set at 0.05 or $5 \%$.

\section{Results}

Fifty-eight mastectomized patients were included and 38 who had undergone conservative breast surgery. In the mastectomy group (Group I) the mean age of patients was 50.5 years (standard deviation: \pm 7.4 ) and in the conservative surgery group (Group II) 53.5 years (standard deviation: \pm 9.2 ).

In Group I, 45 patients (77.6\%) had received only basic education (up to eight years) and, in
Group II, 26 (68.4\%).

The most frequent histological type in both groups was invasive ductal carcinoma $(58.6 \%$ of patients in Group I and $78.9 \%$ in Group II). The mean interval between surgery and assessment of quality of life was 47 months for Group I and 42 months for Group II. Forty-five patients (77.6\%) from Group I underwent chemotherapy and 23 patients $(60.5 \%)$ from Group II. The figures for radiotherapy were $48(82.8 \%)$ and $35(92.1 \%)$ patients in Groups I and II respectively.

Table 1 shows the median SF-36 results and a comparison of Groups I and II. The lowest scores (domain with the worst quality of life) were found in the role emotional domain for both groups (mean 52.6 and 34.5 in Groups I and II, respectively), and the highest (domain with the best quality of life) were in health perception, also again for both groups (mean 70.7 in Group I and 79.1 in Group II).

Comparison of the two groups reveals a significant difference in the domains of physical functioning (with mean scores of 67.5 and 78.2 for Groups I and II respectively; $p=0.04$ ) and pain (mean scores of 64.5 and 77.6 for Groups I and II; $p=0.01$ ). In both cases, Group I had the lower scores (i.e. lower quality of life).

When the patients in the two groups are broken down by age, it can be seen that, of the mastectomized patients, those aged 50 or under had a lower quality of life in the domain of mental health (mean scores 57.8 and 72.4 for Groups I and II respectively; $p=0.05$ ). In the other SF-36 domains there was no significant difference between the groups (Table 2).

Table 1

Median and variation of scores for each domain of the Medical Outcomes Study 36-item Short-Form Health Survey for patients in Groups I and II.

\begin{tabular}{lcc}
\hline SF-36 domain* & $\begin{array}{c}\text { Group I } \\
\text { Median (min-max) }\end{array}$ & $\begin{array}{c}\text { Group II } \\
\text { Median (min-max) }\end{array}$ \\
\hline Physical functioning** & $70(0-100)$ & $83(25-100)$ \\
Role physical & $75(0-100)$ & $75(0-100)$ \\
Pain*** & $62(11-100)$ & $74(31-100)$ \\
Health perception & $77(20-100)$ & $82(42-100)$ \\
Vitality & $65(10-100)$ & $70(30-100)$ \\
Social functioning & $88(0-100)$ & $100(25-100)$ \\
Role emotional & $100(0-100)$ & $67(0-100)$ \\
Mental health & $72(16-100)$ & $72(12-100)$ \\
\hline
\end{tabular}

* SF= Short-Form Health Survey; Mann-Whitney Test: ${ }^{* *} p=0.04 ;{ }^{* * *} p=0.01$. 

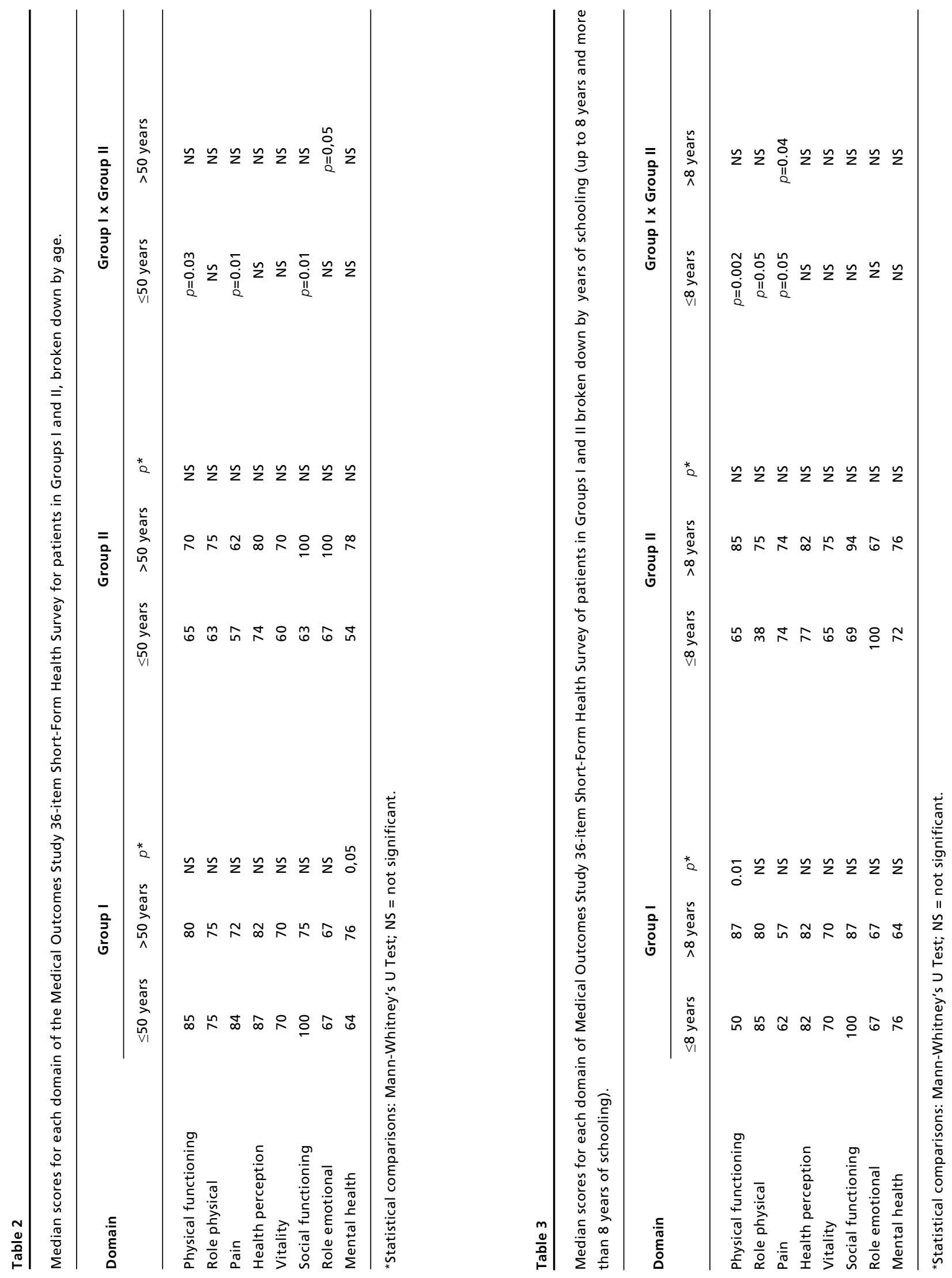
When broken down by years of schooling, the mastectomized patients who had had access only to basic education (eight years of schooling) had a mean score of 61.5 in the domain of physical functioning, which represents a statistically significant difference when compared with patients with more years of schooling (mean score $74.2 ; p=0.01$ ), as shown in Table 3.

Comparison of Groups I and II also reveal that, among younger patients ( $\leq 50$ years), there is a significant difference between the groups in the domains of physical functioning $(p=0.03)$, pain ( $p=0.01$ ) and social functioning $(p=0.01)$. In all three domains, mastectomized patients had a lower quality of life (with means scores of 64.4, 59.8 and 67.9 respectively for these three domains in Group I and 84.1, 81.3 and 88.7 in Group II). Among patients aged over 50 years, there was a difference in the domain of role emotional ( $p=0.05)$, with the patients undergoing conservative surgery scoring lower in this domain (mean scores of 74.0 and 50.5 for Groups I and II respectively, as shown in Table 2).

Also comparing Groups I and II, mastectomized patients who had access only to basic education (up to eight years of schooling) had a lower quality of life in the domains of physical functioning $(p=0.01)$, role physical $(p=0.05)$ and pain $(p=0.05)$ than the patients in Group II with the same level of schooling (mean scores of 61.5, 51.0 and 68.1 respectively for the three domains in Group I and 78.3, 69.7 and 75.7 in Group II). Among patients who attended school for more than eight years, the mastectomized patients had the lower quality of life in the domain of pain, with a statistically significant difference between the two groups (means scores of 54.9 and 80.2 respectively for Groups I and II, $p=0.04$, as shown in Table 3).

\section{Discussion}

The evaluation of the effects of breast cancer surgery on the quality of life of patients is becoming increasingly important in aiding decisions with regard to the type of treatment to be carried out, radical or conservative, when both are possible. ${ }^{11,12,21}$ In this study, mastectomized patients had lower scores in the physical component of quality of life, compared with patients undergoing conservative surgical treatment.

The literature presents controversial results. Warm et al. 12 used SF-12, a short version of SF-36, to compare three groups of patients with breast cancer: those undergoing conservative surgery or mastectomy, with or without reconstruction of the breast and did not observe any difference in quality of life among the groups. Curran et al., ${ }^{6}$ assessing satisfaction in patients undergoing conservative treatment or radical modified mastectomy, report significant benefits for conservative treatment. Parker et al.,11 comparing patients undergoing conservative surgery or mastectomy with or without reconstruction observed, recently after the operation (up to six months) better scores for satisfaction with appearance and in the physical health quality of life domain among patients undergoing conservative surgery. However, with a longer follow-up (from six months to two years) the three groups had identical quality of life scores.

Rabin et al., 8 investigating clinical and demographic factors that interfere in the quality of life of patients with breast cancer, observed that the worse quality of life scores in the physical and psychological domains were associated with mastectomy. Likewise, in the present study, the mastectomized patients had lower scores for aspects involving physical functioning and pain. Kenny et al.,22 assessing 397 patients, obtained a lower score for aspects involving physical functioning in patients undergoing conservative treatment, although these reported greater satisfaction regarding body image. Irwig and Bennetts 23 and Janni et al. 24 also observed a more favorable body image and greater satisfaction in patients undergoing conservative treatment, without reporting differences in terms of general aspects of quality of life. 24,25

It has been shown that the scores for quality of life are directly related to the results of treatment in patients with cancer, especially breast cancer. 21,22 Furthermore, better levels of quality of life tend to be related to a more promising prognosis and the survival rates for patients with a better quality of life (physical and mental components) tends to be higher. ${ }^{22}$ Nevertheless, quality of life tools are not routinely applied to assess the results of cancer surgery. 16

The age on diagnosis influences the quality of life of breast cancer patients. ${ }^{19}$ Previous studies have shown differences in the impact of breast cancer on quality of life for varying age brackets. 26,27

In the present study, the younger women undergoing mastectomy displayed worse mental health than those aged over 50 years. Comparison of the groups revealed that, among younger patients, there was a stronger impact of mastectomy on physicalfunctioning, pain and social functioning, probably because this age group includes women who are more intensively physically and socially active. Other authors 28 have also shown that the diagnosis 
of breast cancer has a greater psycho-social impact on pre-menopausal younger patients, since this group of women is generally more vulnerable to anxieties relating to survival time and the cosmetic side-effects of surgical treatment. They also have to deal with working life, conjugal relations and motherhood, aspects of life that have usually already been resolved and stabilized in older women. 28 Among patients aged over 50 years, however, those undergoing mastectomies presented better results in the role emotional domain, perhaps because mastectomy is culturally related to less fear of recurrence of the disease.

No studies were found in the literature reporting quality of life indicators for level of schooling of patients with breast cancer. In the present study, when the groups were broken down by years of schooling, it was observed that the worset scores for the physical component of the SF-36 (physical functioning, role physical, pain) were to be found among patients undergoing mastectomy who had had access only to basic eduction. This may be attributed to the fact that women with a lower level of education generally carry out work that requires greater physical effort. Future prospective studies with larger samples are necessary to determine the influence of schooling on the quality of life of patients undergoing surgical treatment for breast cancer.

\section{Referências}

1. Budel VM. Câncer da mama no Brasil. [Editorial] Rev Bras Mastologia. 2001; 11: 93.

2. INCA (Instituto Nacional do Câncer). Estimativa 2008: incidência de câncer no Brasil. 2008. [dados online]. [Acessado em março de 2008]. Disponível em: http://www.inca.gov.br/ estimativa/2008/

3. Carramaschi FR, Pinotti JA, Ramos MLC. Tratamento conservador no câncer de mama: das indicações à reconstrução. Rio de Janeiro: Revinter; 2002.

4. Halsted WS. The results of operations for the cure of cancer of the breast performed at Johns Hopkins Hospital from June 1889 to January 1894. Ann Surg. 1894; 20: 497-555.

5. Patey DH, Dyson DH. The prognosis of carcinoma of the breast in relation to type of operation performed. $\mathrm{Br} \mathrm{J}$ Cancer. 1948; 2: 7-13.

6. Curran D, Van Dongen JP, Aaronson NK, Kiebert G, Fentiman IS, Mignolet F, Bartelink H. Quality of life of early-stage breast cancer patients treated with radical mastectomy or breast-conserving procedures: results of EORTC trial 10801. Eur J Cancer. 1998; 34: 307-14.

7. Sheppard LA, Ely S. Breast cancer and sexuality. Breast J. 2008; 14: 176-81.

8. Rabin EG, Heldt E, Hirakata VN, Fleck MP. Quality of life predictors in breast cancer women. Eur J Oncol Nurs. 2008; 12: $53-7$.
In the domains of SF-36 relating to mental health (vitality, mental health, social functioning and role emotional), no difference was found between the groups. Oliveira et al. ${ }^{29}$ did not find any statistical difference in terms of self-esteem among patients undergoing a mastectomy and those undergoing conservative treatment for breast cancer.

Although valid, these results are those of a crosssectional study. Prospective studies, which evaluated the quality of life of patients before and after surgery would provide more consistent evidence of the real impact of surgical treatment for breast cancer on the quality of life of patients.

In fact, a prospective study of patients undergoing mastectomy and later breast reconstruction has shown a significant improvement in quality of life one year after the operation, in all SF-36 domains, except vitality. 30 Breast reconstruction could be a possible way of improving the quality of life of such patients.

It can thus be concluded from the cases studied that patients undergoing mastectomy obtain lower scores on the physical component of the quality of life test, especially in terms of physical functioning and pain, compared with patients undergoing conservative surgery and that this negative impact was more pronounced among younger patients and those with fewer years of schooling.
9. Ohsumi S, Shimozuma K, Kuroi K, Ono M, Imai H. Quality of life of breast cancer patients and types of surgery for breast cancer: current status and unresolved issues. Breast Cancer. 2007; 14: 66-73.

10. Veronesi U, Banfi A, Del Vecchio M, Saccozzi R, Clemente C, Greco M, Luini A, Marubini E, Muscolino G, Rilke F. Comparison of Halsted mastectomy with quadrantectomy, axillary dissection and radiotherapy in early breast cancer: long-term results. Eur J Cancer Clin Oncol. 1986; 22: 1085 9.

11. Parker PA, Youssef A, Walker S, Basen-Engquist K, Cohen L, Gritz ER, Wei QX, Robb GL. Short-term and long-term psychosocial adjustment and quality of life in women undergoing different surgical procedures for breast cancer. Ann Surg Oncol. 2007; 14: 3078-89.

12. Warm M, Gatermann C, Kates R, Mallmann P, Paepke S, Harbeck N, Thomas A. Postoperative sense of well-being and quality of life in breast cancer patients do not depend on type of primary surgery. Onkologie. 2008; 31: 99-104.

13. Al-Ghazal SK, Fallowfield L, Blamey RW. Comparison of psychological aspects and patient satisfaction following breast conserving surgery, simple mastectomy and breast reconstruction. Eur J Cancer. 2000; 36: 1938-43.

14. Milner PC, Nicholl JP. Effects of breast conservation on psychological morbidity. BMJ. 1987; 294: 179-80. 
15. Alderman AK, Wilkins EG, Lowery JC, Kim M, Davis JA. Determinants of patient satisfaction in posmastectomy breast reconstruction. Plast Reconstr Surg. 2000; 106: 76976.

16. Ciconelli RM, Ferraz MB, Santos W, Meinão I, Quaresma MR. Tradução para a língua portuguesa e validação do questionário genérico de avaliação de qualidade de vida SF36 (Brasil SF-36). Rev Bras Reumatol. 1999; 39: 143-50.

17. Ware Jr JE, Sherbourne CD. The MOS 36-item Short-form Health Survey (SF-36): conceptual framework and item selection. Med Care. 1992; 30: 473-483.

18. Siegel S, Castellan Jr NJ. Estatística não-paramétrica para ciências do comportamento. $2^{\mathrm{a}}$ Ed. Tradução de Carmona SIC. Porto Alegre: Artmed; 2006.

19. Langenhoff BS, Krabbe PFM, Wobbes T, Ruers TJM. Quality of life as an outcome measure in surgical oncology. Br J Surg. 2001; 88: 643-52

20. Pusic A, Thompson TA, Kerrigan CL, Sargeant R, Slezak S, Chang BW, Kelzlsouer KJ, Manson PN. Surgical options for early-stage breast cancer: factors associated with patient choice and postoperative quality of life. Plast Reconstr Surg. 1999; 104: 1325-33.

21. Shimozuma K, Sonoo H, Ichihara K, Tanaka K. The prognostic value of quality-of-life scores: preliminary results of an analysis of patients with breast cancer. Surg Today. 2000; 30: 255-261.

22. Kenny P, King MT, Shiell A, Seymour J, Hall J, Langlands A, Boyages J. Early stage breast cancer: costs and quality of life one year after treatment by mastectomy or conservative surgery and radiation therapy. Breast. 2000; 9: 37-44.

23. Irwig L, Bennetts A. Quality of life after breast conservation or mastectomy: a systematic review. Aust N Z J Surg. 1997; 67: 750-4.

Recebido em 10 de novembro de 2008

Versão final apresentada em 22 de maio de 2009

Aprovado em 28 de agosto de 2009
24. Janni W, Rjosk D, Dimpfl TH, Haertl K, Strobl B, Hepp F, Hanke A, Bergauer F, Sommer H. Quality of life influenced by primary surgical treatment for stage I-III breast cancer a long-term follow-up of a matched-pair analysis. Ann Surg Oncol. 2001; 8: 542-8.

25. Ganz PA, Desmond KA, Leedham B, Rowland JH, Meyerowitz BE, Belin TR. Quality of life in long-term, disease-free survivors of breast cancer: a follow-up study. J Natl Cancer Inst. 2002; 94: 39-49.

26. Baider L, Andritsch E, Uziely B, Goldzweig G, EverHadani P, Hofman G, Krenn G, Samonigg H. Effects of age on coping and psychological distress in women diagnosed with breast cancer: review of literature and analysis of two different geographical settings. Crit Rev Oncol Hematol. $2003 ; 46: 5-16$.

27. Avis NE, Crawford S, Manuel J. Quality of life among younger women with breast cancer. J Clin Oncol. 2005; 23:3322-3330.

28. Mor V, Malin M, Allen S. Age differences in the psychosocial problems encountered by breast cancer patients. J Natl Cancer Inst Monogr. 1994; 16: 191-7.

29. Oliveira ACS, Sabino Neto M, Veiga DF, Archangelo SCV, Andrade CHV, Novo NF, Ferreira LM. Mastectomia: impacto na auto-estima das pacientes. Rev Bras Mastol. 2006; 4: 156-60.

30. Veiga DF, Sabino Neto M, Ferreira LM, Garcia EB, Veiga Filho J, Novo NF, Rocha JLBS. Quality of life outcomes after pedicled TRAM flap delayed breast reconstruction. $\mathrm{Br}$ J Plast Surg. 2004; 57: 252-7. 